Revista do Programa de Pós-Graduação em Educação da Unochapecó

ISSN 1984-1566 (on-line) ISSN 1415-8175 (impressa)

\title{
COMPREENSÃO DO PROCESSO DE APRENDIZAGEM: as contribuições da Neuroeducação
}

\author{
ENTENDIENDO EL PROCESO DE APRENDIZAJE: las contribuciones de la \\ Neuroeducación
}
UNDERSTANDING THE LEARNING PROCESS: the contributions of Neuroeducation

\author{
Claudio Sergio da Costa ${ }^{1}$ \\ https://orcid.org/0000-0001-5162-0304 \\ Márcia Finimundi Nóbile ${ }^{2}$ \\ https://orcid.org/0000-0001-7434-3661 \\ Lívia Regina Saiani Crespi ${ }^{3}$ \\ http://orcid.org/0000-0002-0689-3378
}

\section{Resumo}

O artigo objetiva investigar como se dá a compreensão do processo de aprendizagem segundo as contribuições da neuroeducação, haja vista a necessidade de estratégias didáticas que respeitem as especificidades de cada aluno e que promovam condições para que estes avancem em seus processos de aprendizagem. Assim, esse estudo se desenvolveu a partir de uma revisão de literatura científica em artigos publicados entre janeiro de 2009 a janeiro de 2019, na base de dados SciELO. Além desses estudos, também livros sobre o tema foram utilizados para a estruturação do artigo. O período do estudo transcorreu de setembro de 2009 a dezembro de 2019. Com essa revisão de literatura, percebe-se uma convergência entre os estudos dos diversos autores que apontam que os estudos de neuroeducação podem auxiliar no desenvolvimento de estratégias que auxiliam o aluno em sua aprendizagem e com embasamento científico, sobretudo respeitando a forma como o cérebro funciona. $O$ estudo também aponta que os conhecimentos agregados às neurociências podem contribuir substantivamente para a educação e, ainda, melhorar a qualidade de vida do indivíduo e da sociedade.

\footnotetext{
${ }^{1}$ Doutorando em Educação em Ciências pela Universidade Federal do Rio Grande do Sul (UFRGS). Professor do Centro Universitário Barriga Verde/SC. E-mail: claudiopoeta@yahoo.com.br

${ }^{2}$ Doutora em Educação em Ciências pela Universidade Federal do Rio Grande do Sul (UFRGS). Professora do Programa de Pós-Graduação Em Educação em Ciências - Química da Vida e Saúde da Universidade Federal do Rio Grande do Sul (UFRGS).E-mail: marciafinimundi@gmail.com

${ }^{3}$ Doutora em Educação em Ciências pela Universidade Federal do Rio Grande do Sul (UFRGS). Professora da pós-graduação em Neurociências e Gestão Escolar na Faculdade São Marcos de Caxias do Sul/RS. E-mail: saianicrespi@gmail.com
}

\section{Como referenciar este artigo:}

COSTA, C. S.; NOBILE, N. F.; CRESPI, L. R. S. Compreensão do processo de aprendizagem: as contribuições da Neuroeducação. Revista Pedagógica, v. 23, p. 1-28, 2021. 
Palavras-chave: Neuroeducação. Cérebro. Educação. Aprendizagem.

\title{
Resumen
}

El artículo tiene como objetivo investigar cómo entender el proceso de aprendizaje según los aportes de la neuroeducación, dada la necesidad de estrategias didácticas que respeten las especificidades de cada alumno y que promuevan las condiciones para que avance en sus procesos de aprendizaje. Así, este estudio se desarrolló a partir de una revisión de la literatura científica en artículos publicados entre enero de 2009 y enero de 2019, en la base de datos SciELO. Además de estos estudios, también se utilizaron libros sobre el tema para estructurar el artículo. El período de estudio fue de septiembre de 2009 a diciembre de 2019. Con esta revisión de la literatura, existe una convergencia entre los estudios de los distintos autores que señalan que los estudios neuroeducativos pueden ayudar en el desarrollo de estrategias que ayuden al alumno en su aprendizaje y base científica. , especialmente respetando el funcionamiento del cerebro. El estudio también señala que el conocimiento agregado a las neurociencias puede contribuir sustancialmente a la educación y, además, mejorar la calidad de vida del individuo y la sociedad.

Palabras clave: neurociencia. Cerebro. Educación. Aprendizaje.

\begin{abstract}
The article aims to investigate how to understand the learning process according to the contributions of neuroeducation, given the need for didactic strategies that respect the specificities of each student and that promote conditions for them to advance in their learning processes. Thus, this study was developed from a review of the scientific literature in articles published between January 2009 and January 2019, in the SciELO database. In addition to these studies, books on the topic were also used to structure the article. The study period ran from September 2009 to December 2019. With this literature review, there is a convergence between the studies of the various authors who point out that neuroeducational studies can help in the development of strategies that help the student in his learning and scientific basis, especially respecting the way the brain works. The study also points out that the knowledge added to the neurosciences can contribute substantially to education and, also, improve the quality of life of the individual and society.
\end{abstract}

Keywords: Neuroeducation. Brain. Education. Learning.

\section{INTRODUÇÃO}

Passados vinte anos do século XXI e com os avanços advindos das tecnologias de informação e comunicação, para onde se direcionam as inovações no campo das metodologias de ensino? A explosão tecnológica chegou à escola na mesma velocidade que alcançou em outros campos da sociedade ou a metodologia tradicional ainda se faz presente no dia a dia da atividade escolar? Estas questões são pertinentes para se refletir uma vez que a escola é uma instituição formal de ensino pautada em estratégias de ensinar e de aprender. 
Apesar das inúmeras transformações e (re) atualizações ao longo de sua existência e que, paradoxalmente, resiste ao tempo, continua sendo questionada sobre sua adequação aos padrões de ensino exigidos pela atualidade, mas, ao mesmo tempo, é retentora de grande parte das instituições de ensino do país e é valorizada por parte da sociedade que baseia suas crenças de que a escola tradicional é a que melhor forma. "Os estudos devem servir para fazer surgir o interesse para seu objeto. Os estudos só devem durar um certo tempo, enquanto o interesse deve subsistir durante toda a vida" (HERBART, 1982, p.97).

Nesse sentido, argumenta-se que a escola preserva características que a conectam ao modelo tradicional de ensino. No entanto, é necessário também se refletir sobre o termo tradicional relacionado à pedagogia, pois o termo tradicional, quando referido à pedagogia herbartiana, deve ser compreendido no sentido de que ele compôs uma proposta que se constitui como clássica, orientada pela preocupação em que a educação pudesse contribuir para a formação do povo de uma nação e não reduzido às interpretações 'pejorativas' que têm sido dadas ao termo tradicional para significar métodos de ensino desqualificados, autoritários e outros sentidos.

Na ótica do autor, o interesse do aluno é o fio de Ariadne ao longo do qual a instrução educativa avança regularmente, pois a cada momento, "a mente do aluno progride numa determinada direção e numa determinada velocidade. Esse é o efeito do ensino ministrado até o presente, e isso indica ao mestre a direção e a velocidade que ele deve, doravante, a ir em frente" (HERBART, 1982, p. 101).

Posteriormente, os estudos de Herbart não chegaram à academia da mesma forma que de outros pensadores e conforme Saviani (1991) o ensino tradicional passou a fundamentar-se na filosofia da essência, de Rousseau, passando à pedagogia da essência. Essa pedagogia acredita na igualdade essencial entre os seres humanos: a de serem livres, e essa igualdade vai servir de base para estruturar a pedagogia da essência, respaldando o surgimento dos sistemas nacionais de ensino, pautados em uma metodologia de docência tradicional, com o docente no centro do processo de ensino e aprendizagem e o aluno como um indivíduo passivo em aguardo dos conhecimentos transmitidos pelos educadores. Saviani (1991) observa que na década de 1990 o ensino ainda era majoritariamente tradicional e explica que esta abordagem de ensino, 
Esse ensino tradicional que ainda predomina hoje nas escolas se constituiu após a revolução industrial e se implantou nos chamados sistemas nacionais de ensino, configurando amplas redes oficiais, criadas a partir de meados do século passado, quando, consolidado o poder burguês, aciona-se a escola redentora da humanidade, universal, gratuita e obrigatória como um instrumento de consolidação da ordem democrática (SAVIANI, 1991, p.54).

$\mathrm{Na}$ abordagem tradicional de ensino entende-se que a inteligência é uma faculdade que torna o ser humano capaz de armazenar informações, das mais simples às mais complexas. Ainda com Saviani se reflete sobre alguns conceitos que precisam ser bem explicitados. Para o autor, o "clássico" não se confunde com o tradicional e não se opõe, necessariamente, ao moderno e muito menos ao atual. O clássico é aquilo que se firmou como fundamental, como essencial. Pode, pois, se constituir num critério útil para a seleção dos conteúdos do trabalho pedagógico" (SAVIANI, 2003, p.13).

Saviani (2003, p.101) explicita que:

Tradicional é o que se refere ao passado, ao arcaico, ultrapassado. Nesse sentido, nós temos que combater a pedagogia tradicional e reconhecer a validade de algumas das críticas na educação, pois este não se confunde com o tradicional. Clássico é aquilo que resistiu ao tempo, logo sua validade extrapola o momento em que ele foi proposto.

Assim, Saviani faz referência a aspectos que são permanentes, que "se firmam" no âmago da multifacética produção de conhecimento em contextos sociais diversos no processo de formação do gênero humano. Nas entrelinhas de suas citações se autorrevela, de forma implícita, um entendimento de quanto o caráter universal dos conceitos escolares é necessário e significativo na construção de conhecimentos.

Como Saviani, outros pesquisadores também discutiram a questão do ensino tradicional, pautado naquilo que se tornou obsoleto e cuja finalidade é reproduzir sem reflexão. Entre os estudiosos de uma pedagogia mais reflexiva, surgem os escritos de Paulo Freire que trazem à luz o objetivo desse tipo de ensino, baseado na memorização pura e simples dos conhecimentos. A partir de então, outras abordagens metodológicas são estudadas e ganham forças entre os educadores que pensam em uma escola mais inclusiva e com a participação de todos os atores envolvidos no processo de ensinar e de aprender.

Assim, tentando romper com a visão da metodologia tradicional, nas últimas décadas do século XX, Piaget e Vigotski chamam a atenção para a utilização de 
metodologias de estudo qualitativas na educação. Os dois refutam qualquer explicação de desenvolvimento como mero acúmulo quantitativo de aquisições. O método clínicopiagetiano coloca claramente esse ponto. Investigar o raciocínio do aluno não significa simplesmente dar problemas formais para serem resolvidos individualmente, de forma rígida. Segundo o estudioso:

\footnotetext{
O desenvolvimento é um processo que diz respeito à totalidade das estruturas de conhecimento. Aprendizagem apresenta o caso oposto. Em geral, a aprendizagem é provocada por situações - provocada por psicólogos experimentais; ou por professores em relação a um tópico específico; ou por uma situação extrema. Em geral, é provocada e não espontânea. Além disso, é um processo limitado - limitado a um problema único ou a uma estrutura única. Assim, eu penso que desenvolvimento explica aprendizagem, e essa opinião é contrária à opinião amplamente difundida de que o desenvolvimento é uma soma de experiências discretas de aprendizagem (PIAGET, 1964, p.176).
}

Castro Filho (2007) afirma que podemos aprender muito sobre o raciocínio da criança, se criamos tarefas, que embora bem estruturadas, não são rígidas em sua aplicação, nem devem ser resolvidas pelo sujeito isoladamente. O experimentador precisa participar com o aluno na resolução do problema. Pensar o processo de ensino a partir da técnica de resolução de problemas é como fazer o aluno pensar produtivamente. Para que possa pensar produtivamente, uma das possibilidades é a de lhe apresentar problemas que o envolvam, o desafiem e o motivem a querer resolvê-los, mas tais problemas devem ser elaborados, levando-se em consideração o grau de desenvolvimento dos educandos. Para alcançar essa meta, é importante pensar, também, em procedimentos e estratégias que auxiliam na análise, interpretação e na solução de situações em que um ou mais elementos desconhecidos sejam procurados. Nesse sentido, a Neurociências poderá auxiliar a desencadear estratégias que auxiliem na solução de problemas.

Corroborando com as questões relacionadas ao modo de aprender, no século XXI, os estudos derivados de pesquisas neurocientíficas começam a ganhar destaque no campo educacional. Em termos de contribuição ao campo educacional, a Neurociências pode aprimorar o conhecimento do professor frente a sua classe de aula, especialmente no que diz respeito a como o cérebro aprende (LISBOA, 2019). A evolução das pesquisas neurocientíficas tem apontado melhorias no processo de ensino e aprendizagem, uma vez que vem esclarecendo cada vez mais o funcionamento do Sistema Nervoso (SN), 
contribuindo para que os educadores tracem estratégias de ensino diferenciadas (MORALES, 2005; NORONHA, 2008; GUERRA, 2010 apud BARROS, SOUZA, 2013, p. 5).

De acordo com a Neurociências cognitiva, cujo foco de atenção é a compreensão das atividades cerebrais e dos processos de cognição, a aprendizagem humana não decorre de um simples armazenamento de dados perceptuais, e sim do processamento e elaboração das informações oriundas das percepções no cérebro, ou seja, uma teia de relações (DE CARVALHO, 2010).

As pesquisas conduzidas nas áreas transdisciplinares que compõem as Neurociências, durante a busca pelo conhecimento da mente e do comportamento humano, apresenta para diversos outros campos de pesquisa, dentre eles a Educação, possibilidades de desenvolvimento em suas especificidades e de aprimoramento em suas atividades. Estas pesquisas têm como foco de investigação o estudo e a compreensão do sistema nervoso, que é composto pelo cérebro, sistema nervoso central e sistema nervoso periférico. Esta ciência visa entender o desenvolvimento do sistema nervoso de sua função patológica, estrutural, química e funcional (MARQUES, 2016).

Em seus estudos Doring (2015, p. 149-150) reflete também sobre a importância das neurociências, apontando as trocas que acontecem no âmbito cerebral. Em suas palavras:

[...] as neurociências mostram que no cérebro acontece uma troca permanente entre memória e conexões associativas, um processo que gera seus próprios instrumentos de avaliação e assim mantém um processo de aprendizagem circular, entre absorção de informação, consciência e criação de hipóteses, no qual participam fatores subjetivos, fisiológicos, psicoemocionais, entre outros. As atividades do cérebro, por sua vez, são alimentadas por vários níveis de percepção, e seu processamento acontece com a participação de sensações, percepções, emoções, palavras, sons, gestos e posturas corporais. As competências de percepção sensorial são complexas e não representam funções robóticas que podem ser acedidas e desligadas por um clique.

Essa remodelação cerebral constante é um dos fatores que resultam em mudanças comportamentais, o que significa dizer que ocorre a aprendizagem.

Neste estudo são apresentadas algumas reflexões sobre como se dá o processo de aprendizagem em termos neurobiológicos, pautando a presente escrita nas contribuições de autores relacionados aos diferentes campos de pesquisa da Neurociências. Ademais, objetiva-se investigar como se dá a compreensão do processo de aprendizagem segundo as contribuições da neuroeducação, haja vista a necessidade de estratégias didáticas que 
respeitem as especificidades de cada aluno e que promovam condições para que estes avancem em seus processos de aprendizagem.

\section{METODOLOGIA}

A pesquisa teve origem nos estudos desenvolvidos durante as disciplinas teóricas, no Programa de Doutorado em Educação, Ciências e Química para a Vida, oferecido pela Universidade Federal do Rio Grande do Sul, em parceria com as Universidades Federais de Santa Maria, Rio Grande e Universidade do Pampa entre os anos 2018 a 2020.

Trata-se de uma pesquisa qualitativa com uso de revisão bibliográfica em livros e artigos científicos que abordam o tema proposto neste estudo. De acordo com Gil (2008) as pesquisas bibliográficas são indispensáveis, pois buscam a compreensão histórica dos fatos, em um processo de exploração das fontes bibliográficas, de leitura e análise do material para que se possam fazer novas considerações.

De acordo com Boccato (2006, p. 266),

[...] a pesquisa bibliográfica busca a resolução de um problema (hipótese) por meio de referenciais teóricos publicados, analisando e discutindo as várias contribuições científicas. Esse tipo de pesquisa trará subsídios para o conhecimento sobre o que foi pesquisado, como e sob que enfoque e/ou perspectivas foi tratado o assunto apresentado na literatura científica. Para tanto, é de suma importância que o pesquisador realize um planejamento sistemático do processo de pesquisa, compreendendo desde a definição temática, passando pela construção lógica do trabalho até a decisão da sua forma de comunicação e divulgação.

Para a realização da identificação de produções de artigos, optamos por usar a base de dados bibliográficos SciELO - Scientific Electronic Library Online, utilizou-se dos seguintes descritores: neurociências, cérebro, educação e aprendizagem. Foram selecionados artigos publicados entre 2009 e 2019. Ao todo foram elencadas 34 produções em diversas áreas do conhecimento. Para analisar os trabalhos, iniciou-se a leitura dos títulos, seguido da leitura dos resumos e finalmente dos textos completos. Foram suprimidos os artigos repetidos os quais se apresentavam em outros idiomas que não fosse o português, além dos trabalhos que se distanciavam do objetivo proposto para este estudo, totalizando 10 produções. Estas produções serviram como referencial teórico básico para compreensão do processo de aprendizagem segundo as contribuições da 
neuroeducação, bem como autores como Aguilar (2018); Bianchi (2011); Brockington (2011); Carvalho; Barros (2012); Cosenza e Guerra (2011); Costa (2012); Crespi (2017); Lorandi; Azambuja (2014), Maia (2011, 2012); Marques (2016); Moran (2000); Nascimento (2015); Nicola; Neves (2016); Oliveira (2011 e 2014); Orbetelli (2006); Rezende (2008); Rodrigues (2014); Rolim; Sousa (2016); Santos (2001); Silva (2016); Silva; Bezerra (2011); Silva; Morino (2012); Silva; Santana Filha; Fonseca (2018); Souza (2018) e Rotta; Ohlweiler; Riesgo, 2016.

\section{LEVANTAMENTO DE DADOS JUNTO À SCIELO}

A organização dos dados coletados nos permitiu identificar convergências, especificidades e tendências nos estudos relacionados às Neurociências e ao processo de ensino e aprendizagem. Nos dez artigos que serviram de base para esse estudo, constatamos que os pesquisadores discutem a questão da Neurociências aplicada à Educação. Nos estudos realizados por estes autores são palavras recorrentes: Neurociências, aprendizagem, ensino, funcionamento do cérebro, práticas pedagógicas, formação de professores e neuroeducação. Essas convergências sinalizam para a importância de uma visão interdisciplinar quando falamos de processo de ensinar e aprender. O diálogo proposto pela interdisciplinaridade é uma das perspectivas que aparecem nas entrelinhas desses estudos, o que corrobora com os estudos de diversas áreas ligadas a Neurociências e sua interface com os processos educacionais.

No quadro 1, estão listados os artigos científicos selecionados, seus autores e uma síntese de cada um deles. Relacioná-los e apresentar as ideias discutidas auxiliam na compreensão dos estudos que estão sendo realizados, cruzando Neurociências e sua interface com a educação, principalmente nos aspectos relacionados à aprendizagem.

Quadro 1 - Relação dos artigos científicos selecionados, seus objetivos e principais resultados.

\begin{tabular}{|l|l|l|}
\hline Título do Artigo & Citação & Síntese \\
\hline NEUROCIÊNCIA: & DE & As emoções fazem parte da evolução da espécie humana e, \\
UMA ABORDAGEM & CARVALHO; & obviamente, se constituem parte fundamental da aprendizagem \\
SOBRE AS & JUNIOR; DE & $\begin{array}{l}\text { humana. A neurociência compreende o estudo do controle neural das } \\
\text { funções vegetativas, sensoriais e motoras; dos comportamentos de }\end{array}$ \\
EMOÇÕES E O & SOUZA, & locomoção, reprodução e alimentação; e dos mecanismos da atenção, \\
PROCESSO DE & 2019. & memória, aprendizagem, emoção, linguagem e comunicação. \\
APRENDIZAGEM & & \\
\hline
\end{tabular}




\begin{tabular}{|c|c|c|}
\hline $\begin{array}{l}\text { TEORIAS DA } \\
\text { APRENDIZAGEM E } \\
\text { NEUROCIÊNCIA } \\
\text { COGNITIVA: } \\
\text { POSSÍVEIS } \\
\text { APROXIMAÇÕES }\end{array}$ & $\begin{array}{l}\text { DOS } \\
\text { SANTOS } \\
\text { SIMÕES; } \\
\text { NOGARO; } \\
\text { JUNG, } 2018\end{array}$ & $\begin{array}{l}\text { O artigo, de natureza teórica e qualitativa, realiza uma revisão de } \\
\text { literatura sobre possíveis aproximações entre as teorias da } \\
\text { aprendizagem e as pesquisas no campo da neurociência. }\end{array}$ \\
\hline $\begin{array}{l}\text { ENSINO } \\
\text { SUPERIOR, } \\
\text { FORMAÇÃO } \\
\text { DOCENTE E AS } \\
\text { CONSTRIBUIÇÕES } \\
\text { DA NEUROCIÊNCIA } \\
\text { PARA A } \\
\text { EDUCAÇÃO }\end{array}$ & $\begin{array}{l}\text { OLIVEIRA; } \\
\text { SILVA; } \\
\text { RIBEIRO, } \\
2017\end{array}$ & $\begin{array}{l}\text { O presente artigo se consolida como pesquisa teórica por meio da } \\
\text { pesquisa bibliográfica tendo como objetivo a socialização dos } \\
\text { conhecimentos construídos acerca dos desafios e perspectivas no } \\
\text { contexto do ensino superior brasileiro, da formação docente e as } \\
\text { contribuições das descobertas da Neurociência para a Educação. }\end{array}$ \\
\hline $\begin{array}{l}\text { NEUROCIÊNCIA E } \\
\text { EDUCAÇÃO: OS } \\
\text { PERCALÇOS E } \\
\text { POSSIBILIDADES } \\
\text { DE UM CAMINHO } \\
\text { EM CONSTRUÇÃO }\end{array}$ & $\begin{array}{l}\text { DE } \\
\text { BORTOLI; } \\
\text { TERUYA, } \\
2017\end{array}$ & $\begin{array}{l}\text { Os estudos da neurociência no campo da educação são uma } \\
\text { alternativa para repensar as práticas pedagógicas na } \\
\text { contemporaneidade. No campo da neurociência, ancorados em } \\
\text { pesquisas que fazem intersecção entre as ciências do cérebro e } \\
\text { educação, há possibilidade de promoção de novas estratégias } \\
\text { pedagógicas na perspectiva da neurobiologia do aprendizado. O que } \\
\text { os estudos da neurociência trazem de conhecimento sobre o } \\
\text { funcionamento do cérebro possível de elaborar estratégias } \\
\text { pedagógicas? Investigamos a origem e o conceito de neurociência, a } \\
\text { fim de correlacionar os estudos nas áreas da neurociência com a } \\
\text { educação. }\end{array}$ \\
\hline $\begin{array}{l}\text { A NEUROCIÊNCIA } \\
\text { NA FORMAÇÃO } \\
\text { DOS EDUCADORES } \\
\text { E SUA } \\
\text { CONTRIBUIÇÃO } \\
\text { NO PROCESSO DE } \\
\text { APRENDIZAGEM }\end{array}$ & $\begin{array}{l}\text { SOUSA; } \\
\text { ALVES, } 2017 .\end{array}$ & $\begin{array}{l}\text { Investigar como se processa a aprendizagem no cérebro, haja vista a } \\
\text { necessidade de métodos didáticos que criam condições para que o } \\
\text { aluno avance no seu processo de aprendizagem. Essa pesquisa teve a } \\
\text { finalidade de aprofundar conhecimentos teóricos e práticos da } \\
\text { neurociência com relação aos processos mentais na formação do } \\
\text { sujeito. }\end{array}$ \\
\hline $\begin{array}{l}\text { A NEUROCIÊNCIA } \\
\text { E A EDUCAÇÃ̃O E } \\
\text { DISTÂNCIA: UM } \\
\text { DIÁLOGO } \\
\text { NECESSÁRIO }\end{array}$ & $\begin{array}{l}\text { GROSSI; } \\
\text { BORJA, } \\
2016\end{array}$ & $\begin{array}{l}\text { A introdução da neurociência precisa ser considerada em todas as } \\
\text { modalidades de ensino. Dentre essas, na Educação a Distância, que foi } \\
\text { o foco desse estudo, cujo objetivo foi verificar se as ações pedagógicas } \\
\text { desenvolvidas nos Ambientes Virtuais de Aprendizagem dos cursos } \\
\text { técnicos da Rede e-Tec Brasil do Centro Federal de Educação } \\
\text { Tecnológica de Minas Gerais (Rede e-Tec Brasil do CEFET-MG) utilizam } \\
\text { os princípios da neurociência no processo de ensino a partir da } \\
\text { perspectiva dos professores e tutores a distância. }\end{array}$ \\
\hline $\begin{array}{l}\text { NEUROCIÊNCIA E } \\
\text { INCLUSÃO: } \\
\text { IMPLICAÇÕES } \\
\text { EDUCACIONAIS } \\
\text { PARA UM } \\
\text { PROCESSO } \\
\text { INCLUSIVO MAIS } \\
\text { EFICAZ }\end{array}$ & $\begin{array}{l}\text { MARQUES, } \\
2016\end{array}$ & $\begin{array}{l}\text { Estudos na área da neurociência têm sido gradualmente discutidos no } \\
\text { âmbito da educação, numa tentativa de obter subsídios para melhor } \\
\text { compreender o desenvolvimento humano e a multiplicidade de } \\
\text { habilidades do cérebro. Quando aferimos a conjuntura e as } \\
\text { implicações inerentes à educação inclusiva, esse entendimento } \\
\text { transdisciplinar torna-se ainda mais preponderante. Embora a escola } \\
\text { seja um espaço privilegiado de conjugação da diversidade, a sua lógica } \\
\text { de funcionamento tende à homogeneização e à diluição das diferenças } \\
\text { mais marcantes entre sujeitos naturalmente diferentes. }\end{array}$ \\
\hline
\end{tabular}




\begin{tabular}{|c|c|c|}
\hline $\begin{array}{l}\text { UMA REFLEXÃO } \\
\text { SOBRE A } \\
\text { NEUROCIÊNCIA E } \\
\text { OS PADRÕES DE } \\
\text { APRENDIZAGEM: A } \\
\text { IMPORTÂNCIA DE } \\
\text { PERCEBER AS } \\
\text { DIFERENÇAS }\end{array}$ & $\begin{array}{l}\text { GROSSI et } \\
\text { al, 2014. }\end{array}$ & $\begin{array}{l}\text { O objetivo deste estudo foi fazer uma reflexão sobre a importância do } \\
\text { conhecimento da neurociência aplicada à educação, com a finalidade } \\
\text { de perceber as diferenças cognitivas presentes nas salas de aula e, } \\
\text { assim, diminuir as dificuldades de aprendizagem por meio de uma } \\
\text { mudança nos processos de ensino e aprendizagem. }\end{array}$ \\
\hline $\begin{array}{l}\text { A NEUROCIÊNCIA } \\
\text { NA FORMAÇÃO DE } \\
\text { PROFESSORES: } \\
\text { UM ESTUDO DA } \\
\text { REALIDADE } \\
\text { BRASILEIRA } \\
\end{array}$ & $\begin{array}{l}\text { GROSSI; } \\
\text { LOPES; } \\
\text { COUTO, } \\
2014 .\end{array}$ & $\begin{array}{l}\text { Conhecer o funcionamento, potencialidades e limitações do sistema } \\
\text { nervoso possibilitam atender as demandas do educador frente às } \\
\text { dificuldades de aprendizagem, levando a uma contribuição positiva na } \\
\text { prática pedagógica. Por isso a importância de perceber os } \\
\text { fundamentos sobre neurobiologia cognitiva, necessários no processo } \\
\text { ensino e aprendizagem. }\end{array}$ \\
\hline $\begin{array}{l}\text { NEUROCIÊNCIAS E } \\
\text { EDUCAÇÃO: UMA } \\
\text { ARTICULAÇÃO } \\
\text { NECESSÁRIA NA } \\
\text { FORMAÇÃO } \\
\text { DOCENTE }\end{array}$ & $\begin{array}{l}\text { CARVALHO, } \\
\text { 2011. }\end{array}$ & $\begin{array}{l}\text { O texto aborda a possibilidade de inserção dos significativos avanços } \\
\text { da neurociência, como constituintes de saberes disciplinares, nos } \\
\text { cursos de formação de professores. }\end{array}$ \\
\hline
\end{tabular}

Fonte: Pesquisadores (2020).

A síntese dos dados colhidos e apresentados na tabela anterior aponta os achados destes pesquisadores sobre a relação das Neurociências com a Educação. Nas últimas décadas estudos como estes têm sido significativos uma vez que auxiliam os docentes na decisão de quais estratégias poderão ser eficientes para o aprendizado dos alunos. Quando se disponibilizam estudos científicos sobre formas pelas quais se pode melhorar o processo de aprendizagem, auxiliam-se os docentes e os alunos, direcionando as formas de se propor atividades significativas para o desenvolvimento do processo de ensinar e de aprender.

Cumprida esta etapa do estudo, elencou-se os principais pontos pertinentes ao objetivo aqui traçado, estudando com maior ênfase às relações entre Neurociências e Educação, revisando na literatura da área os principais conceitos apontados e de que forma constituem um escopo teórico que nos auxilie na compreensão dos fios que tecem a relação dialógica entre os saberes.

\section{NEUROCIÊNCIAS E EDUCAÇÃO}

Os estudos neurocientíficos ganharam destaque entre 1990 - 2000, nos EUA. Segundo Souza (2014), o então presidente norte-americano George Bush, declarou a 
década de 1990 como a década do cérebro. Entre os principais argumentos estavam: 1) o número grande de estadunidenses afetados por desordens ou transtornos relacionados ao cérebro por ano (cerca de 50 milhões); 2) os grandes gastos públicos com tratamento e reabilitação, estimados em 600 bilhões de dólares anuais; 3) os avanços recentes na área à época; e 4) a revolução tecnológica nos instrumentos utilizados, como o Positron Emission Tomography (PET) e a Ressonância Magnética Nuclear funcional (RMNf) que possibilitariam novas descobertas. Foi então que os resultados das pesquisas neurocientíficas ganharam destaque mundial, popularizando-se e integrando-se ao campo social, político, econômico e educacional.

A educação e a Neurociências são campos de estudo diferentes e possuem objetivos distintos. Enquanto a Neurociências trata das estruturas e do funcionamento do encéfalo, a Educação tem seu objetivo voltado para criar condições de aprendizagem "[...] por isso que as descobertas da Neurociências precisam ser "readaptadas" para que possam contribuir de modo efetivo com a educação" (SIMÕES; NOGARO; ECCO, 2018, p. 88).

Para Nascimento (2011), as descobertas da Neurociências relacionadas diretamente com a aprendizagem constituem uma verdadeira revolução para a área da educação. Os estudos desenvolvidos no campo da Neurociência Cognitiva ocupam-se em pesquisar as funções cognitivas superiores do cérebro humano, entre elas, a aprendizagem, pois as relações entre o cérebro e a aprendizagem tornam-se cada vez mais explícitas uma vez que o cérebro é considerado a fonte de registro e integração dos conhecimentos que permitem ao indivíduo atuar sobre o mundo e adquirir consciência do mesmo. Este é um papel de indiscutível relevância, sendo que tal função nos faz entender a importância dos estudos neurocientíficos. A arquitetura do funcionamento do sistema cognitivo humano ilustra, assim, a interação contígua, contínua e holística da informação entre o envolvimento e o organismo materializada em redes neuronais que asseguram a conexão das unidades de entrada com as unidades de saída, ambas mediadas por redes centrais que permitem a integração, a retenção, a recirculação, a reciclagem, a auto-organização e a retroação da informação, isto é, tornam-na uma rede neurofuncional especialmente apta para aprender.

É importante lembrar que, em Vigotski, a aprendizagem fomenta o desenvolvimento de funções superiores, não é uma função superior em si. Para esse autor: 
As funções psicológicas superiores da criança, as propriedades superiores específicas ao homem, surgem a princípio como formas de comportamento coletivo da criança, como formas de cooperação com outras pessoas, e apenas posteriormente elas se tornam funções interiores individuais da própria criança (VIGOTSKI, 2010, p.699).

As inspirações vigostskianas, de cunho marxista, abordam o desenvolvimento humano a partir da fase mais elementar da estrutura psíquica, desde os processos inferiores involuntários, da ordem do biológico. Quando em contato com os elementos da cultura, essas estruturas psíquicas primitivas evoluem mediadas pela atividade prática do ser humano. Nesse aspecto, a aprendizagem se dá em contexto social, na interação, nas trocas simbólicas.

A Neurociência traz as discussões necessárias para se compreender o momento atual dos estudos sobre o cérebro humano. Compreender como as pessoas aprendem não é um desafio novo para a educação, pois muito se especulou e se especula sobre esta pergunta. A neurociência se alia à educação em busca de uma resposta, buscando contribuir, discutindo a ciência da aprendizagem que apresenta propostas para a aprendizagem ativa, repensando-se o que é ensinado, como se ensina e como se avalia a aprendizagem. A neuroeducação vem se constituindo num campo de pesquisa educacional, com metodologia própria, que se fortalece com as contribuições da neurociência, da psicologia e da pedagogia.

Sob perspectivas diferentes, Vigotski e os estudiosos de sua teoria e os estudos da Neurociência relacionados à educação partilham de aspectos convergentes, pois ambas as teorias consideram o cérebro como um órgão que possibilita a ocorrência do processo de aprendizagem de uma pessoa. Além disso, de acordo com Grossi, Lopes e Couto (2014), aprender tem relação com bases químicas e físicas na função neural do ser humano. Ou seja, quando aprendemos ocorrem modificações nas estruturas do cérebro. É da integração do organismo com o meio cuja mediação se dá pelas vias cerebrais que ocorre a aprendizagem. Com esta compreensão da função do cérebro, podemos afirmar que é ele que propicia a arquitetura biológica para o desenvolvimento das habilidades cognitivas.

A aprendizagem é uma função extremamente elaborada e entre os processamentos cognitivos resultantes de processos cognitivos primários encontram-se a sensação, a 
percepção, a atenção e a memória. Neste contexto e conforme os estudos de Orbetelli (2006), aprender depende de vários fatores, inclusive da motivação do aluno, do desenvolvimento das funções cognitivas e, principalmente, da interação professor-aluno.

Santos (2001) corrobora com essa reflexão ao dizer que o ensino é uma resposta planejada às exigências naturais do processo de aprendizagem. Ou seja, o professor deve se preocupar em acompanhar a aprendizagem de seus alunos e ter uma boa relação com eles. Assim, o papel docente é de fundamental importância para que o processo de aprendizagem se efetive, portanto, na formação docente é de significativa importância o reconhecimento de como se aprende para que se possa desenvolver ferramentas eficazes de ensino.

Há muitos desafios para um professor em sala de aula frente às especificidades de cada aluno. Nem sempre o docente tem condições de adotar uma metodologia que beneficie a todos os alunos ao mesmo tempo, mas é aconselhável que diversifique e alterne as suas estratégias de ensino, podendo, assim, beneficiar o máximo de alunos possíveis.

Nesse sentido, Moran (2000, p. 58), contribui com a reflexão ao comentar que "não podemos dar aula da mesma forma para alunos diferentes, para grupos com diferentes motivações. Precisamos adaptar nossa metodologia, nossas técnicas de comunicação a cada grupo. [...]". De fato, trabalhando em grupo não atenderemos as expectativas de todos, mas devemos procurar encontrar um ponto de equilíbrio entre as expectativas individuais e grupais.

Pensar estratégias diferenciadas para atender os mais diversos grupos de alunos é uma forma de potencializar o processo de ensino-aprendizagem. Ao buscar alternativas que possam tornar o aluno protagonista de seu processo de aprender, o professor auxilia o desenvolvimento de suas potencialidades, desafiando-o a desenvolvê-las a partir das atividades pedagógicas.

Para alcançar tais metas, Carvalho (2010, p. 538), orienta que “[...] é preciso que se abandonem os métodos pedagógicos instrucionais os quais não permitem dar a devida atenção à individualidade, e que se passe a compreender melhor como podemos lidar com certas características pessoais de nossos alunos. [...]" 
Ainda contribuindo para esse estudo, referenciamos Carvalho, Júnior e Souza (2019, p. 8) que fazem essa afirmação:

\begin{abstract}
A partir da Neurociências e do conhecimento neurocientíficos gerado por essa ciência pode-se abrir um diálogo com a educação no sentido de cooperação e parceria. A educação é caracterizada por um processo que envolve aprendizagem e esta é medida pelas propriedades estruturais e funcionais do sistema nervoso, especialmente o cérebro. Entretanto, deve-se considerar que seus conhecimentos não são uma nova proposta de educação.
\end{abstract}

Cabe ressaltar que as contribuições da Neurociências são de suma importância, mas a abordagem metodológica do ensinar e de que forma ocorre a aprendizagem é tarefa do educador. "As ações pedagógicas em sala de aula podem ficar mais eficientes quando este conhece o funcionamento cerebral" (CARVALHO; JUNIOR; SOUZA, 2019, p. 8). Ao se pensar o processo de aprendizagem, é necessário articular os conhecimentos, possibilitando redes de sentido e que auxiliem os alunos em seu processo de aprender. De acordo com Simões, Nogaro e Yung (2018, p. 108):

Incentivar o aluno a construir conhecimentos que realmente lhe façam sentido exige que educadores repensem as metodologias a partir de conhecimentos existentes resultantes das pesquisas do campo da Neurociências. Estes podem auxiliar na escolha de estratégias didáticas com mais chances de se mostrarem eficazes em termos de levar o aluno a aprender.

Segundo Nunes (2017), o professor tem deixado de ser apenas mero transmissor de conteúdo, assumindo a postura de mediador do conhecimento, ou seja, tornando-se ponte entre os saberes que detém e os conhecimentos trazidos pelos educandos. É ele quem deve propor, fazer a diferença e inovar procurando sempre estabelecer um bom relacionamento com seus alunos possibilitando assim um ambiente favorável de aprendizagem.

\title{
O PROCESSO DE APRENDIZAGEM: UMA VISÃO A PARTIR DA NEUROCIÊNCIAS
}

O espaço escolar é um ambiente rico em interações sociais e um dos lugares em que ocorre a aprendizagem. Um dos conceitos de aprendizagem aceito e discutido no campo da Neurociências afirma que "a aprendizagem é um evento sináptico, e, no seu transcurso, 
são produzidas modificações moleculares. Na aprendizagem, há uma etapa de aquisição e outra de consolidação" (ROTTA; OHLWEILER; RIESGO, 2016, p. 36).

A aprendizagem, de forma geral, diz respeito a alterações na conexão entre os neurônios, ou seja, é o processo pelo qual o cérebro reage aos estímulos externos, fortalecendo algumas sinapses e enfraquecendo outras (BROCKINGTON, 2011). Nesse sentido, Bortoli e Teruya (2017, p. 74) afirmam que:

[...] a aprendizagem, do ponto de vista biológico, traduz-se como o processo pelo qual se possibilita a formação e a consolidação das ligações entre as células, ou seja, é resultado de uma experiência sensitiva que provocou alterações químicas e estruturais no sistema nervoso. [...].

A atuação do professor como orientador, mediador e assessor das atividades tem por finalidade fazer emergir do grupo a vontade de aprender; motivar e observar continuamente as reações dos alunos, dando orientações quando necessário; salientar aspectos que não tenham sido observados pelo grupo e que sejam importantes na elaboração do conhecimento do aluno. Quando essa mediação acontece no cotidiano escolar, dizemos que a aprendizagem torna-se efetiva.

De acordo com pesquisas neurocientíficas, o aprendizado e a memória são fases diferentes do mesmo mecanismo progressivo e contínuo. Sem memória, o aprendizado se torna impossível e, sem aprendizado, não existe memória. Aprendizagem, memória e emoção são instâncias interligadas, quando ativadas pelo processo de aquisição do conhecimento. O desafio para a educação não é apenas saber como ensinar ou como avaliar, mas apresentar o conhecimento em um formato que o cérebro aprenda melhor (SOUSA; ALVES, 2017).

Segundo Oliveira (2014), a facilitação da aprendizagem por meio de novas propostas pode alterar para melhor a qualidade de vida das pessoas. Para a ciência da aprendizagem, a pessoa deve assumir o controle da sua própria aprendizagem, além de aprender, também identificar quando entende e quando necessita de mais informações. Partindo desses princípios, a educação pode se beneficiar dos conhecimentos trazidos pelas Neurociências, para melhorar significativamente a capacidade das pessoas se tornarem aprendizes ativos. 
De acordo com Maia (2011), o aprendizado envolve processos complexos e determinadas condições e oportunidades adequadas. Sendo assim, nessa importante função do ponto de vista biológico o Sistema Nervoso (SN) é a figura fundamental para que ocorra a aprendizagem.

Algumas das estruturas do SN mencionadas podem ser observadas na representação gráfica proposta pela Figura 1.

Figura 1: Principais estruturas do Sistema Nervoso

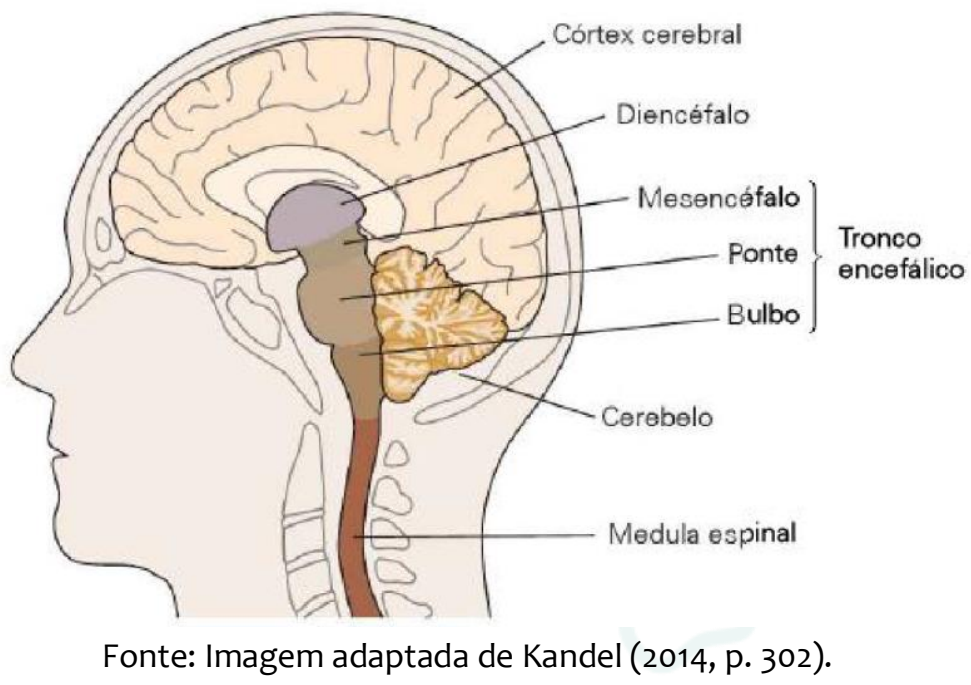

Aguilar (2018, p. 39), ressalta que em épocas passadas “[...] acreditava-se que apenas aprendíamos na infância e parte da idade adulta, hoje, após muitos estudos lemos e ouvimos muito o termo plasticidade cerebral, no qual constata-se que aprendemos durante toda nossa existência". Para Lent (2008), plasticidade cerebral ou neuroplasticidade pode ser amplamente definida como a capacidade do sistema nervoso de responder a estímulos intrínsecos e/ou extrínsecos, reorganizando sua estrutura, função e conexões e pode ocorrer durante o desenvolvimento, em resposta ao ambiente, em apoio à aprendizagem e em resposta às doenças.

O cérebro é constituído por dezenas de bilhões de células nervosas, os neurônios, os quais comunicam-se entre si por meio das sinapses. A aprendizagem, do ponto de vista neurobiológico, consiste na formação e consolidação das ligações sinápticas entre os neurônios (COSENZA; GUERRA, 2011; RELVAS, 2012). As sinapses são os locais que regulam a passagem de informações no SN mediadas por neurotransmissores. Em síntese, os neurônios realizam as trocas de informações, a sinapse é o local que passa essas 
informações e a plasticidade cerebral é o local que recebe e armazena essas informações (COSENZA; GUERRA, 2011).

Segundo Costa (2012, p. 18), os estudos da área de Neurociências voltados à educação "[...] têm mostrado que a memória não é de fato só memorizar, mas um mecanismo fundamental no processo de aquisição do conhecimento [...]”. Nesse sentido, aprender estaria associado ao memorizar. Mas de que forma poder-se-ia memorizar sem cair no mesmo mecanismo tão criticado da escola tradicional?

Oliveira (2014, p. 18), destaca que "aprender não é absorção de conteúdos e exige uma rede complexa de operações neurofisiológicas e neuropsicológicas. [...]”. Sendo assim, fica evidente a importância das Neurociências para o campo educacional, pois, "[...] o processo de aprendizagem se consolida como o processo pelo qual o cérebro age perante os estímulos propiciando as sinapses" (OLIVEIRA; SILVA; RIBEIRO, 2017, p. 117).

Mas como ocorre a aprendizagem? Como sabemos a aprendizagem ocorre no cérebro, suas regiões, lobos, sulcos e reentrâncias, em um trabalho interligado do córtex direito e do córtex esquerdo. Uma das estruturas cerebrais que se destaca no processo de aprendizagem e de consolidação de memórias é o hipocampo, bem como o sistema límbico, responsável pelas emoções; a região central do cérebro é onde está a sede da cognição, da linguagem e da escrita. De forma geral, a leitura e a escrita inicialmente são regidas pela região visual (lobo parietal), e depois acessa outras áreas. A região temporal é responsável por identificarmos os sons e na área temporal verbal que produzimos os sons para que possamos fonar as letras. Já na região occipital ocorre a função da coordenação e reconhecimento de objetos/palavras (NASCIMENTO, 2011).

O sistema límbico, também conhecido como cérebro emocional, é um conjunto de estruturas localizado no cérebro de mamíferos, abaixo do córtex e responsável pela regulação dos processos emocionais e comportamentos sociais, constituído giro do cíngulo, giro para-hipocampal, amígdalas, núcleos anteriores do tálamo, hipotálamo, área septal, núcleos habenulares e corpo mamilar (MACHADO; HAERTEL, 2014).

Algumas das estruturas do sistema límbico mencionadas podem ser observadas na representação gráfica proposta pela Figura 2.

Figura 2: Principais estruturas do Sistema Límbico 


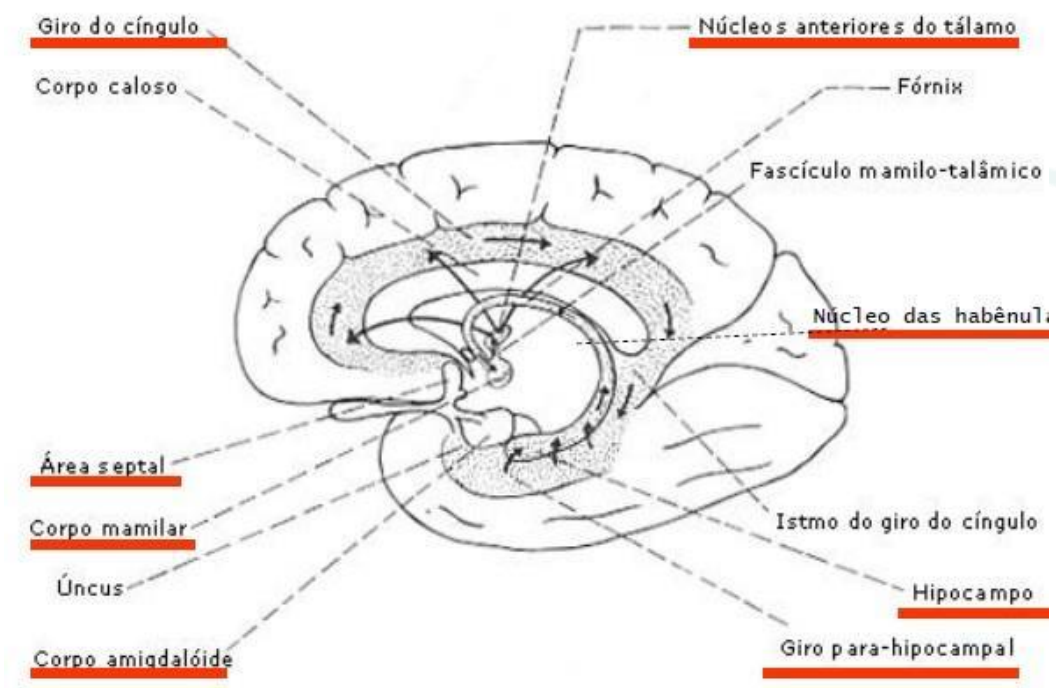

Fonte: Imagem adaptada de Machado; Haertel (2014, p. 262).

A Neurociências, reforçando as descobertas de Luria nas décadas de 1920 e 1930, confirma que as emoções influenciam o processo de aprendizagem. As emoções espelham o desenvolvimento cognitivo, que depende principalmente da motivação, da atenção e da memória (LORANDI; AZAMBUJA, 2014). Para Bianchi (2011), a motivação no âmbito escolar é de extrema importância, pois é isso que desperta a vontade do aluno de aprender e frequentar a escola.

Nascimento (2015, p. 113), ressalta que “[...] A Neurociências vem elucidar que o cérebro tem motivação para aprender, contudo é preciso que seja algo significativo e que o sujeito reconheça como importante". Assim, o cérebro pode ser visto como um sistema dinâmico que tem sua complexidade funcional subsidiada pela sua interação com outros sistemas nele presentes, não podendo ser interpretado como depósito estático para o armazenamento de informação.

Portanto, fica clara a compreensão do processo de aprendizagem através da neurociência, pois, foi possível compreender como ocorre a aprendizagem no cérebro, e entender que o professor tem o papel de despertar a curiosidade do seu aluno, com conteúdos significativos. Dessa forma, a Neurociências “[...] pode ajudar o professor e indicar algumas direções, mas não existe resolução imediata para os problemas, como uma espécie de mágica ou de milagre [...]" (NASCIMENTO, 2015, p. 94).

\section{A IMPORTÂNCIA E OS BENEFÍCIOS DA NEUROEDUCAÇÃO}


A partir da segunda metade do século XX surgiram os primeiros estudos sobre as funções neuronais que são acionadas no processo de aprender. Com os avanços tecnológicos e o incentivo às pesquisas no âmbito da Neurociências Cognitiva, os estudiosos da área têm feito descobertas promissoras de como são feitas as conexões neurais que possibilitam o processo de aprendizagem, trazendo também conceitos de plasticidade cerebral que é inerente a este processo. A partir do desenvolvimento de estudos sobre a especificidade destes conceitos aplicados à educação surgiram os estudos nomeados como neuroeducação.

Segundo Silva, Santana Filha e Fonseca (2018, p. 7), “[...] a Neuroeducação está a serviço dos processos de ensino e aprendizagem, como suporte ao educador para entender o comportamento do aluno diante das situações didáticas”. E por estar a serviço dos processos de ensinar e aprender volta-se também para a pesquisa no campo educacional e, mais especificamente, para o espaço escolar, pois a escola se constitui como espaço privilegiado nas atividades de ensinagem ${ }^{4}$ e aprendizagem.

Os princípios para a estruturação das experiências de aprendizagem que permitem às pessoas utilizarem o que aprenderam em novos cenários foram identificados em pesquisas sobre aprendizagem e transferência. Para Bransford (2007, p.20) “Os estudos de psicologia social, de psicologia cognitiva e de antropologia evidenciam que toda aprendizagem acontece em cenários que apresentam conjuntos específicos de normas e expectativas culturais e sociais[...]".

Fonseca (2009, p 62) acrescenta:

Compreendendo como tais processos evoluem e se interrelacionam sistemicamente no cérebro, estaremos certamente mais próximos do que são efetivamente as funções cognitivas da aprendizagem, podendo, por esse meio, identificar os obstáculos que a bloqueiam ou prevenir disfunções ou dificuldades (ou descapacidades) que a impedem de florescer.

Segundo Bransford (2007) a visão contemporânea a respeito da aprendizagem é de que o conhecimento novo e o entendimento se fazem com base naquilo em que as pessoas

\footnotetext{
4 Ensinagem é o termo cunhado por Léa das Graças Camargo Anastasiou em 1994, para se referir a uma prática social, crítica e complexa em educação entre professor e estudante, "englobando tanto a ação de ensinar quanto a de apreender" (ANASTASIOU; ALVES, 2004, p. 15), dentro ou fora da sala de aula.
} 
acreditam. O autor (2007, p.27) diz "se as ideias e as crenças iniciais dos alunos são ignoradas, a compreensão que eles desenvolvem pode ser muito diferente da que era pretendida pelo professor".

Nesse sentido, é importante que o aluno assuma o controle da própria aprendizagem, aprendendo, também, a identificar quando entende e quando necessita de mais informações. Com estes princípios, a educação pode se beneficiar dos novos conhecimentos da neurociência para melhorar significativamente a capacidade das pessoas se tornarem aprendizes ativos, empenhados em entender e preparados para transferir o que aprenderam na solução de novas situações complexas ou novos problemas.

A neuroeducação pode acrescentar o conhecimento sobre a funcionalidade do cérebro a favor de criar várias estratégias educativas que facilitem a aprendizagem do aluno. Esta ciência “[...] traz novas contribuições com embasamentos na Neurociências para a promoção da inovação das práticas pedagógicas com o objetivo de aumentar a qualidade da educação da escola brasileira e do sucesso escolar das crianças. [...]" (MARQUES, 2016, p. 161).

O futuro da neuroeducação é promissor e pode auxiliar a reverter o quadro de crise educacional brasileiro, mas para que haja essa aproximação entre Neurociências e educação é preciso que o professor conheça e domine o conhecimento atual sobre quais são as estruturas cerebrais que medeiam a aprendizagem, bem como sobre os neurônios, as redes neurais e a neuroplasticidade (CRESPI, 2017).

O cérebro é o único órgão que aprende ensinando e, portanto, quanto maior as interações, maiores serão as redes formadas pelos neurônios que contribuem no processo de aprender. A aprendizagem é uma modificação de comportamento que envolve o desenvolvimento das funções do cérebro. Aprender é um ato complexo que constrói relações entre o pensamento, as emoções, as vias neurais, os neurotransmissores. $O$ ato de aprender envolve a complexidade sobre a qual se move o ser humano em suas relações consigo e com todo o seu entorno. Deve haver um equilíbrio entre cérebro, psiquismo, mente e o ato pedagógico. (TOKUHAMA-ESPINOSA, 2008).

Para que a aprendizagem do aluno se concretize, a prática utilizada pelo docente desempenha um papel importante, pois aprender é produzir novos conhecimentos a partir do já construído socialmente pelas gerações anteriores. Produzir/construir conhecimentos 
ocorre quando o sujeito organiza as informações recebidas, percebe e direciona essas informações e consegue fazer a transposição dos conhecimentos adquiridos de uma situação para outra. Esses são pressupostos que auxiliam a organização do processo de ensinar e de aprender.

Segundo Rodrigues (2014, p. 10), "A Neurociências não mostra "receitas prontas" para estimular a aprendizagem, apenas aponta caminhos que podem ser seguidos por educadores interessados no grande desafio de viabilizar uma aula que facilite funcionamento neural de seu aluno e assim possa promover novas competências cognitivas".

É importante que os professores tenham noções básicas de neurofisiologia e de neurociência para entenderem como o cérebro aprende para que possam aplicar os conhecimentos neurocientíficos sobre a aprendizagem na sala de aula. Como visto, a Neurociências pode contribuir para conhecer melhor os alunos e saber escolher uma estratégia pedagógica que consiga promover uma aprendizagem a todos da classe. Dessa forma, Grossi e Borja (2016, p. 89) explicam ser possível “[...] trabalhar o mesmo conteúdo programático com todos os alunos, utilizando práticas metodológicas que alcancem cada um de forma diferenciada, como um ser único, garantindo a aprendizagem apesar das suas limitações".

Quando o educador compreende o SN ele apropria uma proposta diferenciada para a execução de propostas pedagógicas. No entanto, destaca-se que obter esses conhecimentos não significa exatamente "[...] solucionar desarranjos intelectuais ou que o aluno sofra uma transformação abrupta sobre suas faculdades intelectuais, mas corresponde numa motivação por estímulos adequados para a revelação de um potencial individual [...]" (ROLIM; SOUSA, 2016, p. 5). O professor, em posse desses conhecimentos, pode tornar-se mais ciente sobre os processos neurobiológicos que medeiam a aprendizagem, além de reconhecer que este processo é influenciado por diversos aspectos internos e externos ao aluno que devem ser levados em consideração em uma sala de aula. Neste contexto, Nicola e Neves (2016, p.1) afirmam que:

Os estudos neurocientíficos contribuem para a formação dos profissionais da educação visto que o conhecimento sobre o funcionamento do cérebro tende a ser um auxílio na prática educativa. É importante entendermos como nosso 
cérebro aprende e quais as dificuldades no desenvolvimento de habilidades e de potencialidades por meio de novas técnicas de ensino-aprendizagem, assim os educadores precisam entender como ocorre a aquisição de conhecimento, para ser eficiente o processo ensino-aprendizagem.

Em linhas gerais, a revisão bibliográfica apresentada indica que relacionar os avanços da Neurociências com o processo de ensino aprendizagem é fundamental para entendermos como pensamos e aprendemos, e ademais, reforça que as propostas pedagógicas devem considerar o modo como o cérebro funciona para que a aprendizagem ocorra de maneira efetiva para todos os alunos.

\section{CONSIDERAÇÕES FINAIS}

As pesquisas em Neurociências aplicadas à educação têm por finalidade o desenvolvimento de novos conhecimentos ou comportamentos que ajudam no processo de ensino e aprendizagem. Sabemos que o cérebro é o órgão da aprendizagem, pois as sinapses neuronais promovem uma reorganização constante no sistema neurológico e a aprendizagem tem interferência direta nesse processo. Neste contexto, espera-se que conhecendo de que forma se aprende e como se constrói as teias de relações entre os conhecimentos, o professor pode criar estratégias que auxiliem otimizar o desenvolvimento de potencialidades de aprender do aluno.

Este estudo apontou que conciliar os aportes teóricos advindos da Neurociências com as propostas pedagógicas pode ser uma das possibilidades para melhorar o processo de ensino e aprendizagem, ressaltando que não se trata de propor uma Pedagogia nova, mas de fazer uso de conhecimentos científicos que podem auxiliar na compreensão de como o cérebro aprende, reforçando a ideia de que quando não se pode aprender da maneira como nos ensinam, podemos tentar ensinar da maneira que podemos aprender.

\section{REFERÊNCIAS}

AGUILAR, Renata. Neurociência aplicada à educação: caminhos para facilitar a aprendizagem na sala de aula. São Paulo: Edicon, 2018.

BARROS, Euzeni Almeida de; SOUZA, Roberta Ekuni de. Ensinando Matemática através de jogos e neuroeducação: uma experiencia na sala de recursos. In: PARANÁ. Secretária de 
Revista do Programa de Pós-Graduação em Educação da Unochapecó ISSN 1984-1566 (on-line) ISSN 1415-8175 (impressa)

Estado da Educação. Superintendência de Educação. Os desafios da escola pública paranaense na perspectiva do professor PDE, 2013. Curitiba: SEED/PR., 2013. v. 1 (Cadernos PDE).

BIANCHI, Sara Rebecca. A importância da motivação na aprendizagem do ensino fundamental. 2011. 31f. Trabalho de Conclusão de Curso (Licenciatura Plena em Pedagogia) - Universidade Federal de São Carlos (UFSCar), São Paulo, 2011. Disponível em: < http://www.pedagogia.ufscar.br/documentos/arquivos/trabalhos-de-conclusao-decurso/tcc-2008/a-importancia-da-motivacao-na-aprendizagem-no-ensino-fundamental >. Acesso em: 03 set. 2019.

BOCCATO, Vera Regina Casari. Metodologia da pesquisa bibliográfica na área odontológica e o artigo científico como forma de comunicação. Rev. Odontol. Univ. Cidade São Paulo, São Paulo, v. 18, n. 3, p. 265-274, 2006.

BORTOLI, Bruno de; TERUYA, Teresa Kazuko. Neurociência e Educação: os percalços e possibilidades de um caminho em construção. Imagens da Educação, Maringá, v. 7, n. 1, p. 70-77, 2017. Disponível em: < http://periodicos.uem.br/ojs/index.php/ImagensEduc/article/download/32171/pdf >. Acesso em: 03 nov. 2019.

BRANSFORD, Jonh D.; BROWN, Ann, L.; COCKING, Rodney R. Como as pessoas aprendem. Cérebro mente, experiência e escola. São Paulo, SP: Editora Senac, 2007.

BROCKINGTON, Guilherme. Neurociência e educação: investigando o papel da emoção na aquisição e uso do conhecimento científico. 2011. 23f.Tese (Doutorado em Educação) Universidade de São Paulo (USP), São Paulo, 2011.

CARVALHO, Clecilene Gomes de; JUNIOR, Devanir José Campos; SOUZA, Gleicione Aparecida Dias Bagne de. Neurociência: uma abordagem sobre as emoções e o processo de aprendizagem. Revista da Universidade Vale do Rio Verde, Betim, v. 17, n. 1, p. 1-8, jan./jul. 2019. Disponível em: <

http://periodicos.unincor.br/index.php/revistaunincor/article/view/5619.>. Acesso em: 10 set. 2019.

CARVALHO, Fernanda Antoniolo Hammes de. Neurociências e Educação: uma articulação necessária na formação docente. Trabalho, Educação e Saúde, Rio de Janeiro, v. 8, n. 3, p. 537-550, nov.2010/fev.2011. Disponível em: < http://www.scielo.br/pdf/tes/v8n3/12.pdf>. Acesso em: 10 set. 2019.

CASTRO FILHO, José Aires. Contribuições da psicologia para a aprendizagem escolar. Revista de Educação-AEC, p. 20-36, 2007.

COSENZA, Ramon M.; GUERRA, Leonor B. Neurociência e educação: como o cérebro aprende. Porto Alegre: Artmed, 2011. 
Revista do Programa de Pós-Graduação em Educação da Unochapecó ISSN 1984-1566 (on-line) ISSN 1415-8175 (impressa)

COSTA, Fabiana Pinheiro da. Memória não é só decoreba: um estudo sobre a ação docente como potencializadora da aprendizagem. 2012. $18 \mathrm{f}$ Trabalho de Conclusão de Curso (Licenciatura em Pedagogia) - Universidade Federal do Rio Grande do Sul (UFRGS), Porto Alegre, 2012. Disponível em: <

https://www.lume.ufrgs.br/bitstream/handle/10183/67876/000872742.pdf?sequence $=1>$. Acesso em: 21 nov. 2019.

CRESPI, Livia. Neurociências e Educação: Interlocuções entre o conhecimento científico, prática docente e formação de pedagogos. 2017. $58 \mathrm{f}$ Dissertação (Mestrado em Educação em Ciências) - Universidade Federal do Rio Grande do Sul (UFRGS), Porto Alegre, 2017. Disponível em: < https://www.lume.ufrgs.br/handle/10183/159515. >. Acesso em: 03 set. 2019 .

DIAS, Maria Sara de Lima. Introdução às leituras de Lev Vygotski: debates e atualidades na pesquisa. 2019. Disponível em: < http://repositorio.utfpr.edu.br/jspui/handle/1/4583.>. Acesso em: 15 set. 2019 .

DORING, Katharina. Perceber, mover, criar-processos de transformação. Revista Pedagógica, v. 17, n. 35, p. 136-162, 2015. Disponível em: < https://bell.unochapeco.edu.br/revistas/index.php/pedagogica/article/view/3059.>. Acesso em: 10 set. 2019.

FONSECA, Vitor. Cognição, neuropsicologia e aprendizagem: abordagem neuropsicológica e psicopedagógica. Petrópolis, RJ: Editora Vozes, 2009.

GIL, Antônio Carlos. Métodos e técnicas da pesquisa social. São Paulo: Atlas, 2008.

GROSSI, Márcia Gorett Ribeiro; BORJA, Shirley Doweslei Bernardes. A Neurociência e a Educação e Distância: um Diálogo Necessário. Revista Tempos e Espaços em Educação, São Cristóvão, Sergipe, Brasil, v. 9, n. 19, p. 87-102, mai./ago. 2016. Disponível em: < https://gestaoeducacaoespecial.ufes.br/sites/gestaoeducacaoespecial.ufes.br/files/field/a nexo/neurociencia_e_ambiente_virtuis.pdf>. Acesso em: 10 out. 2019.

GROSSI, Márcia Gorett Ribeiro; LOPES, Aline Moraes; COUTO, Pablo Alves. A neurociência na formação de professores: um estudo da realidade brasileira. FAEEBA, Salvador, v. 23, n. 41, p. 27-40, jan/jun 2014. Disponível em: < https://www.revistas.uneb.br/index.php/faeeba/article/viewFile/821/579 >. Acesso em: 10 out. 2019.

HERBART, Johann . Pädagogische Schriften: Erster Band; Kleinere pädagogische Schriften, v. 1. Stuttgart, 1982. In: HILGENHEGER, Norbert. Johann Herbart. Tradução e organização: José Eustáquio Romão. Recife: Fundação Joaquim Nabuco, Editora Massangana, 2010.

LENT, Roberto. Neurociência da mente e do comportamento. Rio de Janeiro: Guanabara Koogan, 2008. 
Revista do Programa de Pós-Graduação em Educação da Unochapecó

ISSN 1984-1566 (on-line) ISSN 1415-8175 (impressa)

LORANDI, Aline; AZAMBUJA, Flávia. Neurociência: memória e funções executivas na articulação entre língua portuguesa e consciência política. Signo, Santa Cruz do Sul, v. 39, n. 67, p. 101-109, jul./dez. 2014. Disponível em: <

http://online.unisc.br/seer/index.php/signo/article/viewFile/5027/3813 >. Acesso em: 03 out. 2019 .

MACHADO, Angelo; HAERTEL, Lucia Machado. Neuroanatomia funcional. $3^{\circ}$ ed. São Paulo: Atheneu, 2014.

MAIA, Heber (Org). Neuroeducação: a relação entre saúde e educação. Rio de Janeiro: Wak Editora, 2011.

MARQUES, Stela. Neurociência e inclusão: implicações educacionais para um processo inclusivo mais eficaz. Revista Trama Interdisciplinar, v. 7, n. 2, 2016.

MORAN, José. Mudar a forma de ensinar e aprender. Revista Interações, São Paulo, v. 5, [s.n], p. 57-72, 2000. Disponível em: <

http://www.eca.usp.br/prof/moran/site/textos/tecnologias_eduacacao/uber.pdf $>$. Acesso em: 10 set. 2019.

NASCIMENTO, Maria José Soares do. O papel da neurociência no processo de ensino aprendizagem. 2011. 41f. Monografia (Pós-Graduação Neurociência Pedagógica) - AVM Faculdade Integrada, Rio de Janeiro, 2011. Disponível em:

<http://www.avm.edu.br/docpdf/monografias_publicadas/C206339.pdf>. Acesso em: 10 set. 2019.

NASCIMENTO, Rosilene Maria do. Dificuldades de aprendizagem: as contribuições da neurociência para o ensino de matemática. 2015. 94,113f. Dissertação (Mestrado em Educação) - Universidade Cidade de São Paulo (UNICID), São Paulo, 2015. Disponível em: < https://www.unicid.edu.br/wp-content/uploads/2016/04/Disserta\%C3\%A7\%C3\%A30Rosilene-Maria-do-Nasimento.pdf >. Acesso em: 03 out. 2019.

NICOLA, Patrícia da Silva; NEVES, Sandra Garcia. As contribuições das neurociências ao processo de ensino-aprendizagem. In: VII CONCCEPAR: Congresso Científico da Região Centro-Ocidental do Paraná, 7, 2016, Campo Mourão. Anais do VII CONCCEPAR: Congresso Científico da Região Centro-Ocidental do Paraná... Campo Mourão: Grupo Integrado, 2016. Disponível em: http://conccepar.grupointegrado.br/resumo/ascontribuicoes-das-neurociencias-ao-processo-de-ensinoaprendizagem/480/1465. Acesso em: 06 out. 2019.

NUNES, Tarcia Gabriela Holanda. A relação professor (a)/aluno (a) no processo de ensino aprendizagem. 2017. Disponível em: < https://repositorio.ufpb.br/jspui/handle/123456789/4105>. Acesso em: 06 out. 2019. 
Revista do Programa de Pós-Graduação em Educação da Unochapecó ISSN 1984-1566 (on-line) ISSN 1415-8175 (impressa)

OLIVEIRA, Gilberto Gonçalves de. Neurociências e os processos educativos: um saber necessário na formação dos professores. Educação Unisinos, v. 18, n. 1, p. 13-24, jan./abr.2014.

OLIVEIRA, Gilberto Gonçalves de. A pedagogia da neurociência: ensinando o cérebro e a mente. Curitiba: Appris: 2011.

OLIVEIRA, Josiani Julião Alves de.; SILVA, Paula Ravagnani.; RIBEIRO, Priscila Maitara Avelino. Ensino superior, formação docente e as contribuições da neurociência para a educação. Revista CAMINE: Caminhos da Educação, Franca, v. 9, n. 1, p. 106-125, 2017. Disponível em: < https://seer.franca.unesp.br/index.php/caminhos/article/view/2053.>. Acesso em: 10 set. 2019 .

ORBETELLI, Sheila. Histórias que precisam ser conhecidas: reflexividade de professores em ações plurais na escola pública. ETD, Campinas, v. 7, n. esp., p. 111-116, jun. 2006. Disponível em: < http://www.brapci.inf.br/_repositorio/2010/01/pdf_79785deb27_0007747.pdf >. Acesso em: 10 set. 2019 .

PIAGET, Jean. Seis estudos de Psicologia. Rio de Janeiro: Forense, 1967. Título original: Six études de psychologie. 1964.

RELVAS, Marta Pires. Neurociência na prática pedagógica. Rio de Janeiro: Wak, 2012.

REZENDE, Mara Regina Kossoski Felix. A neurociência e o ensino-aprendizagem em ciências: um diálogo necessário. 28f.Dissertação (Mestrado em Ensino de Ciências na Amazônia).Universidade do Estado do Amazonas (UEA), Manaus, 2008. Disponível em: http://www.pos.uea.edu.br/data/area/titulado/download/10-9.pdf. Acesso em: 15 out. 2019.

RODRIGUES, Thaize Barreto. Neurociência na Aprendizagem e Educação: uma reflexão sobre a sua potencial aplicação no ensino superior. 2014. 79f. Monografia (Especialista em Docência do Ensino Superior) - AVM Faculdade Integrada, Brasília, 2014. Disponível em: < https://www.avm.edu.br/docpdf/monografias_publicadas/posdistancia/51726.pdf >. Acesso em: 21 nov. 2019.

ROLIM, Camila; SOUSA; Raimunda Aurilia Ferreira de. A contribuição da neurociência na pedagogia. In: Conedu Congresso Nacional de Educação, III., 2016, Natal. Colóquio Internacional Educação, Cidadania e exclusão: didática e avaliação... Natal: Realize, 2016. Disponível em: http://www.editorarealize.com.br/revistas/conedu/trabalhos/TRABALHO_EV056_MD1_SA 4_ID4172_11082016143729.pdf. Acesso em: 06 out. 2019.

ROTTA, Newra Tellechea; OHLWEILER, Ligia; RIESGO, Rudimar dos Santos (Org.). Transtornos da aprendizagem: abordagem neurobiológica e multidisciplinar. 2.ed. Porto Alegre, RS: ArtMed, 2016. 
Revista do Programa de Pós-Graduação em Educação da Unochapecó

ISSN 1984-1566 (on-line) ISSN 1415-8175 (impressa)

SANTOS, Sandra Carvalho dos. O processo de ensino-aprendizagem e a relação professor-aluno: aplicação dos sete princípios para a boa prática na educação de ensino superior. Caderno de pesquisas em administração, São Paulo, v. 8, n. 1, p. 69-82, jan/mar. 2001. Disponível em: <

http://www.sinprodf.org.br/wpcontent/uploads/2012/01/tx_5_proc_ens_aprend.pdf >. Acesso em: 10 set. 2019 .

SAVIANI, Dermeval. Pedagogia histórico-crítica. São Paulo: Autores Associados, 2003.

SAVIANI, Dermeval. Escola e democracia. 24. ed. São Paulo: Cortez, 1991.

SILVA, Fiderisa; MORINO, Carlos Richard Ibãnez. A importância das neurociências na formação de professores. Momento, Rio Grande, v. 21, n. 1, p. 29-50, 2012. Disponível em: https://periodicos.furg.br/momento/article/viewFile/2478/2195. Acesso em: 18 out. 2019.

SILVA, Paula Ravagnani; OLIVEIRA, Josiani Julião Alves de. Os recursos da neurociência no âmbito da educação. In: II Seminário Internacional de Pesquisa em Políticas Públicas e Desenvolvimento Social, 2, 2016, Franca. Anais do II Seminário Internacional de Pesquisa em Políticas Públicas e Desenvolvimento Social, Franca: 2, 2016, p. 1-10. Disponível em: https://www.franca.unesp.br/Home/Pos-graduacao/-

planejamentoeanalisedepoliticaspublicas/iisippedes2016/00000.pdf. Acesso em: 18 out. 2019.

SILVA, Luciano Pontes da; SANTANA FILHA, Ligia; FONSECA, Laerte. Neurociência e etnomatemática: uma articulação possível. In: XII Colóquio Internacional "Educação e Contemporaneidade”, 2018, São Cristóvão. Anais do XII Colóquio Internacional

“Educação e Contemporaneidade”, São Cristóvão: 12, 2018. p. 1-12. Disponível em: https://ri.ufs.br/bitstream/riufs/9017/47/Neurociencia_e_etnomatematica_uma_articulaca o_possivel.pdf. Acesso em: 11 out. 2019.

SIMÕES, Estela Mari Santos; NOGARO, Arnaldo; YUNG, Hildegard Susana. Teorias de aprendizagem e neurociência cognitiva: possíveis aproximações. Revista COCAR, Pará, v. 12, n. 23, p. 85-113, jan./jun. 2018. Disponível em: <

https://periodicos.uepa.br/index.php/cocar/article/view/1720.>. Acesso em: 02 de out. 2019 .

SOUSA, Anne Madeliny Oliveira Pereira de; ALVES, Ricardo Rilton Nogueira. A neurociência na formação dos educadores e sua contribuição no processo de aprendizagem. Revista Psicopedagogia, v. 34, n. 105, p. 320-331, 2017. Disponível em: < http://pepsic.bvsalud.org/scielo.php?script=sci_arttext\&pid=S0103-84862017000300009/ >. Acesso em: 02 out. 2019.

SOUZA, Fernando Olga de. Análise do comportamento e a neurociência: uma perspectiva histórica. 2014. 77f.Dissertação (Mestrado em psicologia experimental: análise do comportamento) - Pontifícia Universidade Católica de São Paulo PUC SP, São Paulo, 2014. 
Disponível em:

<https://tede2.pucsp.br/bitstream/handle/16722/1/Fernando\%20Olga\%20de\%20Souza.pdf>. Acesso em: 10 set. 2019.

TOKUHAMA-ESPINOSA, T. N. The scientifically substantiated art of teaching: a study in the development of standards in the new academic field of neuroeducation (mind, brain, and education science). 2008. Disponível em:

<http://www.educacionparatodos.com/pdf/Dissertation.pdf >. Acesso em: 13 nov. 2019.

VIGOTSKI, Lev Semionovich. Quarta aula: a questão do meio na pedologia. Psicologia USP, v. 21, n. 4, p. 681-701, 2010. Disponível em <http://www.scielo.br>. (Originalmente publicado em 1935). Acesso em 14 fev. 2021.

Recebido em: 16-01-2021

Aprovado em: 21-02-2021

Publicado em: 05-04-2021 